\section{SM Journal of Pediatric Surgery}

\author{
Article Information \\ Received date: Oct 19, 2015 \\ Accepted date: Oct 30, 2015 \\ Published date: Nov 04, 2015 \\ *Corresponding author
}

Vicki L Mahan, St. Christopher's Hospital for Children, Drexel University College

of Medicine, USA, Email: Vicki.Mahan@ tenethealth.com

Distributed under Creative Commons CC-BY 4.0

\section{Routine Use of Pulse Oximetry in the Newborn to Detect Critical Congenital Heart Disease}

\author{
Vicki L Mahan* \\ St. Christopher's Hospital for Children, Drexel University College of Medicine, USA
}

\section{Editorial}

Critical Congenital Heart Disease's (CCHD's) are potentially life-threatening cardiac abnormalities where the systemic or pulmonary circulation is dependent on a patent ductus arteriosus and include those with duct-dependent pulmonary blood flow, inter-circulatory mixing, and systemic hypoperfusion. The seven main CCHD's screening targets for neonatal pulse oximetry are hypoplastic left heart syndrome, pulmonary atresia (with intact ventricular septum), Tetralogy of Fallot, total anomalous pulmonary venous return, transposition of the great arteries, tricuspid atresia and truncus arteriosus. Early diagnosis improves outcomes. Systematic review and metaanalysis of pulse oximetry screening for critical congenital heart defects in asymptomatic newborn babies revealed that the overall sensitivity was $76.5 \%$ and specificity was $99.9 \%$. The false-positive rate was low when it was done after 24 hours from birth [1]. The American Heart Association and the American Academy of Pediatrics suggest that routine pulse oximetry done on asymptomatic newborns after 24 hours of life but before discharge may detect critical CHD, incurs very low cost, and there is a low risk of harm [2]. European studies suggest that screening is cost-effective in identifying newborns with CCHD [3,4]. Over half of babies discharged with CHD detected in the first year of life were discharged from the hospital with a normal routine neonatal examination and the 6 week exam missed one-third of the patients [5]. In many countries, births are not attended and infants are discharged within hours of birth without medical evaluation by a qualified practioner. CCHD's will go undetected in this setting.

The screening study is done on the child in the well baby nursery at 24 to 48 hours of age or shortly before discharge if $<24$ hours of age. The screen is done by a qualified screener using a pulse oximeter and probes calibrated for the newborn's right hand and either foot. A negative screen is defined as an $\mathrm{O} 2$ saturation $\geq 95 \%$ in the right hand or foot and $\leq 3 \%$ difference between the right hand and foot. If the $\mathrm{O} 2$ saturation is $90 \%$ to $<95 \%$ in the right hand and foot or $>3 \%$ difference in saturation between the right hand and foot, the screen is repeated in 1 hour. A negative screen is again defined as an $\mathrm{O} 2$ saturation $\geq 95 \%$ in the right hand or foot and $\leq 3 \%$ difference between the right hand and foot. If the screen again shows that the O2 saturation is $90 \%$ to $<95 \%$ in the right hand and foot or $>3 \%$ difference in saturation between the right hand and foot, the screen is again repeated in 1 hour and a negative screen is again defined as an $\mathrm{O} 2$ saturation $\geq 95 \%$ in the right hand or foot and $\leq 3 \%$ difference between the right hand and foot. A positive screen requires further evaluation to determine if the findings are respiratory related or cardiac related.

The local situation is key. Cardiac services are standard of care in many countries and are becoming more common in developing countries. As undetected CCHD is a cause of sudden neonatal death with patients dying at home or in the emergency department [6], early detection improves the survival of neonates and infants and improves long-term quality and quantity of life for patients identified early in life. Missing the diagnosis or detecting CCHD at an advanced stage portends poor outcomes.

Implementation of the screening program in developing countries not having access to comprehensive primary healthcare services may magnify the discrepancies in management and outcomes of congenital heart disease. However, early detection may improve overall neonatal care and outcomes, provide basic medical care, and foster an independent approach to diagnosis and management of CCHD acceptable to the population served.

The Newborn Foundation is working with global health agencies, clinicians, Nongovernmental Organizations (NGOs) and the medtech industry to implement the Birth Oximetry Routine for Newborns (BORN) Project. The project is aligned with the World Health Organization's Safe Childbirth Checklist and was presented at the International Conference on Birth Defects in the Developing World in 2013. The education-and-implementation model will provide clinical education, data, and a screening framework for accurate measurements of hypoxemia in newborns. 
The inaugural pilot project in Sichuan Province China will evaluate nearly 50.000 newborns at county and village birth facilities. In its efforts to reduce neonatal mortality and to trigger additional NGOs and international health bodies to support pulse oximetry evaluation as a standard practice for all newborns regardless of geography, the Newborn Foundation joined with the Every Newborn Action Plan (ENAP) and newborn pulse oximetry screening is being implemented in a growing number of countries around the world. Evidence shows that using pulse oximetry and having reliable oxygen sources in district and provincial hospitals in developing countries can reduce infection-related newborn death rates by as much as $35 \%$. A growing number of countries are implementing newborn pulse oximetry screening with the goal of reducing newborn mortality throughout the world.

Implementation of newborn pulse oximetry on a worldwide level should improve referral of the high risk newborn to facilities able to evaluate and manage CCHD. Newborn screening by pulse oximetry is an invaluable tool to improve overall newborn mortality rates, diagnose CCHD, and to help communities decide on the care patients with CCHD may need. Many of these patients may be able to undergo interventional or surgical correction of their CHD and lead a normal life and be able to contribute to their families and communities. Delay in diagnosis may result in early death or development of irreversible lung and/or cardiac disease. Early diagnosis will help the family and community make an informed decision regarding treatment of the newborn with CCHD.

\section{References}

1. Thangaratinam S, Brown K, Zamora J, Khan KS, Ewer AK. Pulse oximetry screening for critical congenital heart defects in asymptomatic newborn babies: a systematic review and meta-analysis. Lancet. 2012; 379: 24592464.

2. 2. Mahle WT, Newburger JW, Matherne GP, Smith FC, Hoke TR, Koppel $\mathrm{R}$, Gidding SS, Beekman RH, and Grosse SD. "Role of Pulse Oximetry in Examining Newborns for Congenital Heart Disease: A Scientific Statement from the American Heart Association and American Academy of Pediatrics." Circulation. 2009;120: 447-458.

3. 3. de-Wahl Granelli A, Wennergren M, Sanberg K, Mellander M, Bejlum C, Inganäs L, Eriksson M, Segerdahl N, Agren A, Ekman-Joelsson BM, Sunneggårdh $\mathrm{J}$, Verdicchio $\mathrm{M}$, and Ostman-Smith I. "Impact of Pulse Oximetry Screening on the Detection of Duct Dependent Congenital Heart Disease: A Swedish Prospective Screeening Study in 39,821 Newborns." BMJ. 2009;338:a3037.

4. 4. Roberts TE, Barton PM, Auguste PE, Middleton LJ, Furmston AT, and Ewer AK. "Pulse Oximetry as a Screening Test for Congenital Heart Defects in Newborn Infants: A Cost-effectiveness Analysis." Arch Dis Child. 2012; 97: 221-226.

5. Wren C, Richmond S, Donaldson L. Presentation of congenital heart disease in infancy: implications for routine examination. Arch Dis Child Fetal Neonatal Ed. 1999; 80: F49-53

6. Chang RK, Gurvitz M, Rodriguez S. Missed diagnosis of critical congenital heart disease. Arch Pediatr Adolesc Med. 2008; 162: 969-974. 